\title{
Tsafon
}

Revue d'études juives du Nord

73 | 2017

Connaissance de la Shoah : témoignages, enseignements, visites

\section{Van Goethem et Patricia Ramet (eds), Drancy- Auschwitz, 1942-1944, Juifs de Belgique déportés via la France}

\section{Danielle Delmaire}

\section{(2) OpenEdition}

\section{Journals}

Édition électronique

URL : https://journals.openedition.org/tsafon/334

DOI : $10.4000 /$ tsafon.334

ISSN : 2609-6420

\section{Éditeur}

Association Jean-Marie Delmaire

Édition imprimée

Date de publication : 1 juin 2017

Pagination : 188-189

ISSN : 1149-6630

Référence électronique

Danielle Delmaire, "Van Goethem et Patricia Ramet (eds), Drancy-Auschwitz, 1942-1944, Juifs de

Belgique déportés via la France », Tsafon [En ligne], 73 | 2017, mis en ligne le 31 mai 2018, consulté le 24 juin 2021. URL : http://journals.openedition.org/tsafon/334; DOI : https://doi.org/10.4000/tsafon.334

Ce document a été généré automatiquement le 24 juin 2021.

Tsafon. Revues d'études juives du Nord 


\title{
Van Goethem et Patricia Ramet (eds), Drancy-Auschwitz, 1942-1944, Juifs de Belgique déportés via la France
}

\author{
Danielle Delmaire
}

\section{RÉFÉRENCE}

Goethem Van et Patricia Ramet (eds), Drancy-Auschwitz, 1942-1944, Juifs de Belgique déportés via la France, Malines, Kazerne Dossin, 397 pages.

1 «Le 10 mai 1940, plusieurs milliers de Juifs allemands 'suspects' ont été arrêtés par les autorités belges, déportés en France et là enfermés dans des camps» (p. 5), la III République puis le Gouvernement de Vichy qui ne souhaitaient pas les accueillir s'en sont vite débarrassés en les arrêtant ou en les livrant aux Allemands. Cet épais ouvrage, écrit en trois langues (flamand, français et anglais), "suit le destin de ces déportés " (p.5), retrace le parcours de quelques-uns d'entre eux et publie leurs photos. Il fait suite à une série de quatre autres volumes édités également par Kazerne Dossin, intitulée Mecheln-Auschwitz 1942-1944 et parue en 2008, évoquant le sort des déportés de la caserne Dossin de Malines et rassemblant les photographies de 18522 personnes!

Serge Klarsfeld, pour le Mémorial de la Shoah à Paris, est l'auteur de l'avant-propos tandis que Herman Van Goethem a rédigé l'introduction. Puis l'ouvrage se divise en trois parties: d'abord la présentation du contexte de ces déportations rappelle l'histoire de la France et de la Belgique de 1940 à 1944 par Laurence Schram, conservatrice au Musée de la Déportation et des Droits de l'Homme à Malines, Herman Van Goethem et Alexandre Doulut; suit la description des 79 transports qui ont amené à la mort les Juifs déportés de France et dans lesquels se trouvaient des Juifs de Belgique, par Dorien Styven; enfin Patricia Ramet a rassemblé en plus d'une soixantaine de pages l'index, présenté par ordre alphabétique, des noms des déportés juifs de Belgique via la France. 
3 La première partie, bien documentée, retrace fort utilement, en une centaine de pages, l'histoire complexe de la politique raciste et antisémite des États des deux pays. Les Juifs étrangers établis en Belgique pour avoir fui les persécutions en Pologne puis dans l'Allemagne et l'Autriche nazies ne pouvaient attendre aucune aide, aucun secours de la Belgique ni même de la France pour ceux qui n'ont pas attendu d'être arrêtés comme " suspects » et se sont réfugiés en France dès l'invasion allemande.

Dès lors, pour ceux qui sont pris dans la nasse vichyste ou allemande, une vie indigne commence dans les camps de la zone sud, non occupée (!) puis à Drancy. Une carte de ces camps et des différentes zones qui constituent la France de 1940 à 1944 illustre magnifiquement la situation. Suit la description des différents camps et du camp de transit de Drancy. En une vingtaine de pages, sont présentés les 70 transports, année après année (trois ans au total). Le récit du terrible sort des quelques enfants originaires de Belgique et refugiés à la Maison d'Izieu vient clore cette première partie.

5 La seconde partie livre les visages de la plupart des déportés, réfugiés de Belgique, qui se trouvent dans chacun des transports qui quittent la France vers l'extermination en Pologne. Les visages d'une partie de ces déportés manquent mais ceux qui nous regardent, dans ces pages, disent toute l'iniquité qui les a fait mourir: des hommes d'âge mûr, des femmes, des vieillards, des enfants, très jeunes parfois. Pour chacun des transports, un cas particulier est évoqué.

6 Les visages nous parlent mais les chiffres disent aussi le côté infernal du processus à exterminer. Dans chaque transport parti de France, se trouvent des Juifs originaires de Belgique mais, du 10 août au 18 septembre 1942, 18 transports emmènent 3784 Juifs qui ont fui la Belgique et les auteurs ont pu retrouver 2909 photos, soit les visages des $3 / 4$ de ces déportés. Le transport qui véhicule le plus de grand nombre de ces Juifs est le $\mathrm{n}^{\circ} 28$ qui quitte Drancy pour Auschwitz le 4 septembre 1942, soit 453 personnes et 316 photos retrouvées. Le transport 44 du 9 novembre 1942 ne déporte qu'un seul Juif de Belgique et sa photo est retrouvée. En dehors de ces tristes mois de l'été et de l'automne 1942, les transports sont plus espacés et le nombre de Juifs originaires de Belgique moins important. Toutefois, les transports 50 et 51, qui se dirigent vers Maïdanek les 4 et 6 mars 1943, ont encore dans leurs wagons 215 et 163 Juifs de Belgique dont les photos de 160 et 115 d'entre eux ont été retrouvées.

7 L'index de la troisième partie livre la liste des déportés juifs originaires de Belgique, par ordre alphabétique des noms de famille avec indication si la photo a été retrouvée et si le déporté a pu survivre. Suit enfin une brève bibliographie.

On l'aura compris, cet ouvrage est d'abord un mémorial qui soustrait de l'oubli et de la disparition totale les déportés juifs de Belgique arrêtés et déportés de France. Les pages introductives placent les déportations dans le contexte de la guerre et de la fuite vers la France qui ne sut pas les protéger et même les livra, pour certains, aux Allemands. 